\title{
Ubiquitous presence of paracetamol in human urine: sources and implications
}

\author{
Hendrik Modick, Tobias Weiss, Georg Dierkes, Thomas Brüning and Holger M Koch \\ Institute for Prevention and Occupational Medicine of the German Social Accident Insurance, Institute of the \\ Ruhr-Universität Bochum (IPA), Bürkle-de-la-Camp-Platz 1, 44789 Bochum, Germany
}

Correspondence should be addressed to HM Koch; Email: koch@ipa-dguv.de

\begin{abstract}
$\mathrm{N}$-acetyl-4-aminophenol (acetaminophen/paracetamol, NA4AP) is one of the most commonly used over-the-counter analgesic and antipyretic drugs. Recent studies have reported anti-androgenic effects of NA4AP in vitro and possible associations between intrauterine exposure to NA4AP and the development of male reproductive disorders in humans. NA4AP is also a major metabolite of aniline (phenylamine), representing $\mathbf{7 5 - 8 6 \%}$ of the aniline dose excreted in urine. Aniline is an important large-volume intermediate in several industrial processes. Besides individuals in various occupational settings with aniline exposure, the general population is also known to be ubiquitously exposed to aniline. In this article, we provide an overview of the recent literature concerning the intake of NA4AP during pregnancy and the possible anti-androgenic effects of NA4AP as well as literature concerning its known metabolic precursor aniline. We also present new research data, including the first human biomonitoring data on NA4AP excretion in urine, showing ubiquitous NA4AP body burdens in the general population at a wide range of concentrations. We found a small but significant impact of smoking on urinary NA4AP concentrations. We further present preliminary data on NA4AP excretion after therapeutic acetaminophen use, after aniline exposure in an occupational setting, and during a controlled fasting study (excluding oral exposure to both aniline and acetaminophen). Our findings indicate exposure to aniline (or aniline-releasing substances) as well as nutrition (next to the direct use of acetaminophen as medication) as possible sources of internal body burdens of NA4AP.

Reproduction (2014) 147 R105-R117
\end{abstract}

\section{Introduction}

Since its market placement in the 1950s, acetaminophen, in Europe generally referred as paracetamol ( $\mathrm{N}$-acetyl-4aminophenol, CAS no. 103-90-2, abbreviated herein as NA4AP (acetaminophen/paracetamol)), is one of the top-selling and heavily used over-the-counter (OTC) analgesic (pain-relieving) and antipyretic (feverreducing) nonsteroidal anti-inflammatory drugs (NSAIDs). NA4AP is also approved for veterinary use in

This paper forms part of a special issue of Reproduction on Endocrine Disrupters. This article was presented at the 7 th Copenhagen Workshop on Endocrine Disrupters, 28-31 May 2013. The meeting was supported by the Danish Ministry of the Environment - Environmental Protection Agency as an activity under the Danish Centre on Endocrine Disrupters. Publication of this special issue has been supported by the Society for Reproduction and Fertility. The opinions or views expressed in this special issue are those of the authors, and do not necessarily reflect the opinions or recommendations of the Danish Ministry of the Environment - Environmental Protection Agency or the Society for Reproduction and Fertility. The Guest Editors for this special issue were Anna-Maria Andersson, Hanne Frederiksen, Niels Erik Skakkebæk, Rigshospitalet, Denmark, Kenneth M Grigor, Western General Hospital, Edinburgh, UK and Jorma Toppari, University of Turku, Finland. the European Union, for example, in poultry and swine meat production (European Commission 2010). However, it has long been overlooked that NA4AP is the major metabolite of aniline (phenylamine, CAS no. 62-53-3). Aniline is an important building block in the chemical industry, for example, in the production of rubber, pesticides, and colorants used in food, cosmetics, and textiles. It has been known for some time that the general population is ubiquitously exposed to aniline through environmental as well as occupational sources.

In two recent human biomonitoring (HBM) pilot studies carried out by our group, we have reported the ubiquitous excretion of NA4AP in urine in the general population (Modick et al. 2013, Dierkes et al. 2014). We observed maximum urinary NA4AP concentrations well in the milligram per liter range even after the exclusion of individuals using NA4AP-containing pharmaceuticals or individuals with possible occupational exposure to aniline.

The ubiquitous presence of a pharmacologically active substance in the general population per se warrants further investigation. Additionally, recent in vitro studies as well as epidemiological studies suggest NA4AP as a possible risk factor for male developmental disorders in humans (Kristensen et al. 2012, Thiele et al. 2013). 
Therefore, in this article, we give an overview of the available data on possible detrimental effects of NA4AP on male sexual development, its role in aniline metabolism, recent HBM data, and possible sources of internal body burdens of NA4AP in the general population in environmental and occupational settings. We complement this article with new research data on NA4AP HBM from our institute.

\section{Intakes and usage of NA4AP}

\section{NA4AP in human NSAIDs}

NA4AP along with aspirin is one of the most commonly used OTC drugs for the treatment of pain and fever. The German pharmaceutical register lists 55 formulations containing NA4AP as a single drug or as a pharmaceutical ingredient in combination drugs that are approved for sale in Germany (Landschneider 2011). In 2008, two of the ten top-selling pharmaceuticals in Germany contained NA4AP (Glaeske et al. 2009). About 35.5 million packages of NA4AP, each containing 20-40 pills, were sold in Spain in 2009 (Ortiz de García et al. 2013).

NA4AP and NA4AP-containing pharmaceuticals are also commonly used by pregnant women (Black \& Hill 2003). Several large birth cohort studies have reported general intake of OTC analgesics during pregnancy (see Table 1). Reasons for the intake of OTC analgesics were mainly headache $(66.5 \%)$ followed by muscle ache $(8.7 \%)$ and other types of pain $(8.7 \%$ in sum). Fever, inflammation, and cold accounted for $6.9 \%$ (Kristensen et al. 2010).

Variations between these studies may be explained by the study sizes as well as demographic factors such as ethnicity, educational status, and age (Werler et al. 2005). There is also an influence based on whether the

Table 1 Frequency of analgesic use during pregnancy in several birth cohort studies.

\begin{tabular}{|c|c|c|}
\hline Cohort & $\begin{array}{c}\text { Frequency of intake } \\
\text { (at least once during } \\
\text { pregnancy) }(\%)\end{array}$ & Reference \\
\hline $\begin{array}{l}\text { Slone Epidemiology Center } \\
\text { Birth Defects Study (USA), } \\
n=7563\end{array}$ & 69.8 & $\begin{array}{l}\text { Werler et al. } \\
\text { (2005) }\end{array}$ \\
\hline $\begin{array}{l}\text { National Birth Defects } \\
\text { Prevention Study (USA), } \\
n=2970\end{array}$ & 65.5 & $\begin{array}{l}\text { Werler et al. } \\
\text { (2005) }\end{array}$ \\
\hline $\begin{array}{l}\text { Danish National Birth } \\
\text { Cohort, } n=88142\end{array}$ & 50.3 & $\begin{array}{l}\text { Rebordosa } \\
\text { et al. (2008) }\end{array}$ \\
\hline $\begin{array}{l}\text { Danish and Finnish Birth } \\
\text { Cohort, } n=2297\end{array}$ & $26.1-57.2^{\mathrm{a}}$ & $\begin{array}{l}\text { Kristensen } \\
\quad \text { et al. (2011) }\end{array}$ \\
\hline $\begin{array}{l}\text { Eden Mother-Child Cohort } \\
\quad(\mathrm{FR}), n=903\end{array}$ & $81^{\mathrm{b}}$ & $\begin{array}{l}\text { Philippat et al. } \\
\text { (2011) }\end{array}$ \\
\hline $\begin{array}{l}\text { Generation R Study (NL), } \\
n=3184\end{array}$ & $29.9^{b}$ & $\begin{array}{l}\text { Snijder et al. } \\
(2012)\end{array}$ \\
\hline
\end{tabular}

${ }^{\mathrm{a}}$ Depending on whether inquiry was done by a questionnaire or by a telephone interview. ${ }^{\mathrm{b}}$ Mild analgesics in general. inquiry was realized through self-administered questionnaires or by telephone interviews. In a study carried out in a Danish cohort (Kristensen et al. 2010), 285 mothers completed both a questionnaire and a telephone interview. In the questionnaire, 30.9\% (88 of 285) of the mothers reported the use of analgesics as opposed to $57.2 \%$ in the telephone interview (163 of 285). The authors of this study came to the conclusion that many mothers did not consider OTC analgesics as medication and therefore strongly underreported its use unless they were specifically asked.

However, the available data clearly indicate that OTC analgesics are also commonly used by pregnant women. Large studies (Werler et al. 2005, Rebordosa et al. 2008) have indicated NA4AP and NA4AP-containing pharmaceuticals as the most commonly used products.

NA4AP can freely pass the placenta (Weigand et al. 1984). NA4AP and its metabolites were detected in the urine of neonates after their mothers had taken NA4AP a few hours before delivery (Levy et al. 1975a). Furthermore, as NA4AP is excreted in breast milk after therapeutic dosing, neonates can be exposed to NA4AP. Bitzén et al. (1981) monitored the levels of NA4AP in plasma and breast milk in three lactating women after the use of a single $500 \mathrm{mg}$ dose of NA4AP. In breast milk, maximum concentrations of $\sim 4 \mathrm{mg} N \mathrm{NAAP} / \mathrm{l}$ were found within $2 \mathrm{~h}$ of intake. Therefore, the authors estimated a dose of $<0.1 \%$ of the maternal dose for infants in $100 \mathrm{ml}$ breast milk (Bitzén et al. 1981). Comparable values were estimated by Berlin et al. (1980) with 22 lactating women who were given a $650 \mathrm{mg}$ dose of paracetamol. The authors evaluated the ingestible amount of NA4AP for neonates to be $0.04-0.23 \%$ of the maternal dose in $90 \mathrm{ml}$ breast milk. Neither NA4AP nor its metabolites could be detected in the neonates' urine samples $3-5 \mathrm{~h}$ after maternal dosing $(2 \mathrm{~h}$ after nursing at peak maternal milk levels; Berlin et al. 1980). In a study carried out in 1987, NA4AP could be detected in the urine samples of six neonates whose mothers were given NA4AP, although at considerably higher doses of 1-2 g. The authors detected free NA4AP and its glucuronide and sulfate conjugates in all the urine samples, whereas cysteine and mercapturic acid conjugates could be detected in the urine samples of five of the six neonates (Notarianni et al. 1987). Thus, not only mothers but also fetuses and neonates are exposed to NA4AP.

\section{NA4AP in veterinary/meat production use}

According to Commission Regulation (EU) 37/2010 on pharmacologically active substances and their classification regarding maximum residue limits in foodstuffs of animal origin (European Commission 2010), NA4AP is approved for veterinary use in Europe. The regulation restricts the usage of NA4AP for porcine species. However, according to a report of the Committee for Veterinary Medicinal Products, which belongs to the 
European Agency for the Evaluation of Medicinal Products (EMEA), NA4AP is also used in cattle and poultry for the treatment of fermentation disorders, painful diseases, and pyrexia (Committee for Veterinary Medicinal Products 1999). In Regulation (EU) 37/2010, no maximum residue limit, and therefore no withdrawal period after the treatment of animals with NA4AP, was established. Suppliers of veterinary medicine formulations offer NA4AP as $30 \%$ solutions $(30 \mathrm{~g} / 100 \mathrm{ml})$ in package sizes of up to $20 \mathrm{I}$. Interestingly, one study conducted in the mid-1960s reported a stimulatory effect of NA4AP on chicken growth. NA4AP given at dietary levels between 0.1 and $2.0 \mathrm{~g} / \mathrm{kg}$ feed was found to increase weight gain in roosters and in hens by $6.5-10 \%$ compared with that in the controls (Dikstein et al. 1966).

To our knowledge, NA4AP has not been part of largersized national food monitoring programs in the past few years. In 2002, NA4AP was part of the monitoring program of the German national residue control plan, processed by the German Food Safety Authority. In sum, 221 samples of animal products or food products of animal origin, inter alia, including poultry, veal, cattle, swine, and milk were tested for NA4AP. Residues of NA4AP could not be detected in any of the samples analyzed (Federal Ministry of Food, Agriculture and Consumer Protection 2002). However, the report of the national residue control plan does not include any information on either the analytical methods applied or their limits of quantification, which makes interpretation of the results difficult. In contrast to antibiotics, published analytical methods for the determination of NA4AP in foodstuffs of animal origin are rather rare. Hu et al. (2012) published a method for the determination of 30 NSAID residues including NA4AP in swine muscle by ultra-HPLC coupled with tandem mass spectrometry. The detection limit was $0.4 \mu \mathrm{g} / \mathrm{kg}$ and the quantification limit was $1.0 \mu \mathrm{g} / \mathrm{kg}$. The authors reported trace residues of NA4AP (and other NSAIDs) in 100 samples of imported swine muscle with a positive rate of about $7 \%$. A similar method for the determination of NA4AP among other NSAIDs in bovine milk and muscle tissue was developed by Gentili et al. (2012). The authors applied the method to eight milk samples and eight bovine muscle tissue samples. No residues of NA4AP could be detected in any of the samples (Gentili et al. 2012). Love et al. (2012) detected NA4AP in feather meal (a byproduct made from poultry feathers), which can be used as an additive in animal feed in concentrations ranging from 15.1 to $155 \mu \mathrm{g} / \mathrm{kg}$ ( $83 \%$ positive samples). These authors suggested contaminated feather meal as a possible route for re-entry of pharmaceuticals into the food chain.

\section{NA4AP as the major metabolite of aniline}

NA4AP and its conjugates appear in the metabolism of aniline. Kao et al. (1978) found NA4AP (mainly in its glucuronic acid- or sulfate-conjugated form) to be the major urinary metabolite in pigs $(\sim 77 \%)$, sheep $(\sim 85 \%)$, and rats $(\sim 65 \%)$. Between 2 and $13 \%$ of NA4AP was excreted as free NA4AP among all three species. Other urinary metabolites were $O$-conjugates of 2 - and 4-aminophenol (5.5-25\% of the aniline dose) and acetanilide $(0.5-3.4 \%$ of the aniline dose) (Kao et al. 1978). Figure 1 shows the simplified metabolic pathway of aniline according to the findings of Kao et al. (for a more detailed aniline metabolism pathway scheme, see German Federal Ministry of Environment (2011)). A similar excretion pattern for aniline can be expected in humans (German Research Foundation 1992). Lewalter \& Korallus (1985) found NA4AP (in concentrations up to the $\mathrm{mg} / \mathrm{l}$ range) and acetanilide (in the $\mu \mathrm{g} / \mathrm{l}$ range) in the urine samples of workers following occupational exposure to aniline (air concentrations below the occupational threshold limit of $7.7 \mathrm{mg} / \mathrm{m}^{3}$ air) (German Research Foundation 1992). NA4AP was also detected as a metabolite after acute aniline intoxication (IwersenBergmann \& Schmoldt 2000). Dierkes et al. (2014) detected acetanilide and NA4AP in the urine samples of six volunteers known to be exposed to aniline. Further in-depth quantitative and kinetic investigations of human aniline metabolism do not exist to our knowledge.

The ubiquitous body burden of aniline in the general German population has been well described previously. Total urinary aniline has routinely been determined after hydrolysis to cleave possible aniline conjugates such as acetanilide (el-Bayoumy et al. 1986, Riffelmann et al. 1995, Ward et al. 1996, Weiss \& Angerer 2002). Aniline, determined in this way, has been recently found in over $90 \%$ of the urine samples collected from 1004 individuals from the general German population (Kütting et al. 2009; Table 2). Extrapolation of these aniline levels, considering that NA4AP is the major metabolite of aniline, would result in urinary NA4AP levels up to the $\mathrm{mg} / \mathrm{l}$ range. Variations between these studies can be explained by different study sizes, the times the studies were conducted, and mostly by differences in the analytical methods, especially concerning the hydrolysis of acetanilide.

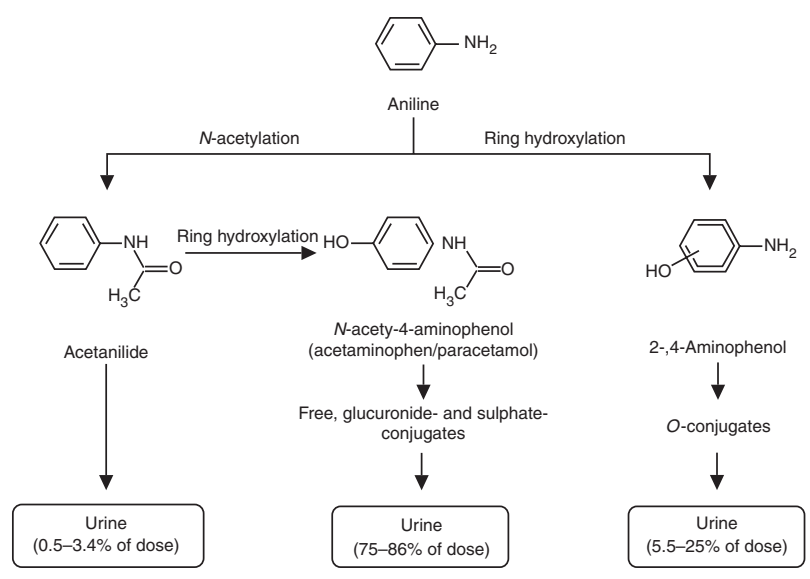

Figure 1 Simplified metabolism of aniline. 
Table 2 Human biomonitoring data of aniline in the general population.

\begin{tabular}{|c|c|c|c|c|}
\hline \multirow[b]{2}{*}{ Study } & \multirow[b]{2}{*}{ Participants } & \multicolumn{3}{|c|}{$\begin{array}{l}\text { Urinary aniline concentrations } \\
\qquad(\mu \mathrm{g} / \mathrm{l})\end{array}$} \\
\hline & & Median & $\begin{array}{c}\text { 95th } \\
\text { percentile }\end{array}$ & Range \\
\hline $\begin{array}{l}\text { el Bayoumy et al. } \\
\text { (1986) }\end{array}$ & 28 & 2.9 & NA & ND-8.8 \\
\hline $\begin{array}{l}\text { Riffelmann et al. } \\
\quad(1995)\end{array}$ & 16 & 0.8 & NA & ND-5.1 \\
\hline Ward et al. (1996) & 26 & 2.9 & NA & NA \\
\hline $\begin{array}{l}\text { Weiss \& Angerer } \\
\quad(2002)\end{array}$ & 160 & 3.7 & 7.9 & $0.4-13.0$ \\
\hline Kütting et al. (2009) & 1004 & 3.1 & 14.3 & $0.05-384$ \\
\hline
\end{tabular}

$\mathrm{NA}$, not available; ND, not detectable.

To date, neither the specific aniline metabolite acetanilide nor NA4AP (with the exception of the studies carried out by Modick et al. (2013) and Dierkes et al. (2014)) has been used in HBM studies to determine exposure to aniline.

The main routes of aniline exposure in the general population have been postulated to be pesticide residues, pharmaceuticals, colorants used in food, cosmetics, and textiles, and cigarette smoke (German Federal Ministry of Environment 2011). Palmiotto et al. (2001) detected aniline in the indoor air of homes at levels ranging from $5 \mathrm{ng} / \mathrm{m}^{3}$ to about $33 \mathrm{ng} / \mathrm{m}^{3}$, with higher values being observed in the homes of smokers. Aniline was also detected in the air of several public buildings and in outdoor air, highlighting the ubiquitous presence of aniline in the environment (Palmiotto et al. 2001).

\section{Evidence for the developmental toxicity of NA4AP}

\section{In vitro and animal studies}

Animal studies carried out in the 1980s have already suggested an association between prenatal exposure to analgesics and reduced masculinization. In 1989, it was found that the administration of aspirin to mice inhibited the synthesis of prostaglandins (PGs) in male and female fetuses (Gupta 1989). PGs are supposed to be involved, inter alia, in processes such as early male sexual development and masculinization and hormone regulation (Gupta 1989, Amateau \& McCarthy 2004).

Kristensen et al. (2010) showed that intrauterine exposure of Wistar rats to NA4AP led to a significant reduction in the anogenital distance of male offspring. In the same study, the authors reported a reduced production of PGD2 and testosterone in ex vivo fetal rat testes (Kristensen et al. 2010). A study carried out by Kristensen et al. (2011) that many presumed endocrine-disrupting chemicals (EDCs) dose dependently inhibited PGD2 synthesis in mouse Sertoli cell lines. The observed effect was comparable within the tested analgesics, which included NA4AP, aspirin, and ibuprofen, and was even higher than the measured effect of other known EDCs such as $n$-butylparaben and bisphenol A. Therefore, the authors concluded that pharmaceutical PG inhibitors such as NA4AP, aspirin, and ibuprofen may act as endocrine disruptors. The authors were also able to pinpoint the suppression of PG synthesis to the inhibition of cyclooxygenase (COX) enzymes (Kristensen et al. 2011). It is thought that NA4AP acts as an inhibitor of COX enzymes, although the precise mechanism of action is still unclear (Hinz et al. 2007).

Kristensen et al. (2012) showed that exposure to NA4AP and aspirin inhibited testosterone production in a rat organotypic culture system. The levels of testosterone produced by fetal Leydig cells were lower by about $10-50 \%$ than those of the controls when exposed to NA4AP in concentrations ranging from 0.1 to $100 \mu \mathrm{M}$, confirming their previous in vivo findings. However, the anti-androgenic effects of NA4AP were not correlated with the inhibition of PGD2 synthesis in this fetal testis culture system (Kristensen et al. 2012).

\section{Human data}

\section{Data on endocrine effects}

A recent study carried by Albert et al. (2013) has investigated the direct effects of NA4AP (and two other NSAIDs) using whole human testis in organotypic culture and the $\mathrm{NCl}-\mathrm{H} 295 \mathrm{R}$ human steroidogenic cell line. The exposure levels to NA4AP were chosen based on the estimation of serum concentrations in adult men after exposure to a standard dose of $1 \mathrm{~g}$ NA4AP, $10^{-5}$ and $10^{-4} \mathrm{M}$ respectively. Exposure to $10^{-5}$ and $10^{-4} \mathrm{M}$ NA4AP dependently decreased testosterone secretion by the human testis after $24 \mathrm{~h}$ of exposure by 18 and $30 \%$ compared with that in the controls. Following $48 \mathrm{~h}$ of exposure, testosterone concentrations were not significantly decreased further at either dosages. Testosterone concentrations in the $\mathrm{NCl}-\mathrm{H} 295 \mathrm{R}$ human steroidogenic cell line were significantly lower than those in the controls after $24 \mathrm{~h}$ treatment with $10^{-4} \mathrm{M}$ NA4AP. The effect was not significant after $48 \mathrm{~h}$ of exposure and with the $10^{-5} \mathrm{M}$ NA4AP concentration.

Furthermore, $24 \mathrm{~h}$ of exposure to $10^{-4} \mathrm{MNA} 4 \mathrm{AP}$ was also found to lower PG concentrations significantly in the human testis by $28 \%$ for PGD2 and 38\% for PGE2 compared with the control concentrations (Albert et al. 2013). However, the limitations of this study were the evaluations of exposure levels and the durations of exposure. Although the exposure levels were chosen based on the estimated serum concentrations as that occurring after therapeutic use, the resulting testicular concentrations in adult men are unknown and rather difficult to determine.

Mazaud-Guittot et al. (2013) used an in vitro system based on the cell culture of human fetal testes exposed to NA4AP and its metabolite $\mathrm{N}$-arachinodyl4-phenolamine (AM404; see 'Metabolism of 
acetaminophen and aniline' section) and other NSAIDs at concentrations ranging from $10^{-4}$ to $10^{-7} \mathrm{M}$. Endocrine-disrupting properties were investigated through measures of testosterone, anti-Müllerian hormone (AMH), insulin-like factor 3 (INSL3), and PGs (PGD2 and PGE2) (Mazaud-Guittot et al. 2013). The authors found significant inhibition of INSL3 production in samples exposed to NA4AP and AM404, with a significant dose-response relationship indicating a decrease in INSL3 production with an increasing dose of NA4AP. The measured trend for AMH production to be increased by NA4AP was not significant. Significant inhibitory effects of NA4AP on PGE2 production were observed, whereas the trends for the inhibition of PGD2 synthesis were not significant. Neither NA4AP nor AM404 had any significant effect on testosterone production in this study. The authors suggested the analgesic-induced inhibition of INSL3 production to be the mechanism by which analgesics increase the risk of cryptorchidism because several mutations of the INSL3 gene or its receptors were found to be associated with cases of cryptorchidism in humans (Foresta et al. 2008).

\section{Associations between acetaminophen intake during pregnancy and reproductive disorders}

In a study from the Danish National Birth Cohort with 88142 pregnant women and their liveborn singletons with questionnaire information about NA4AP use during the first trimester, no association of NA4AP with an increased prevalence of congenital abnormalities was found (Rebordosa et al. 2008).

Since 2011, the number of studies that have found further evidence of the association between NA4AP use during pregnancy and reproductive disorders has increased. A study from the Danish National Birth Cohort using the data of 47700 mothers and their male offspring found that cumulative NA4AP exposure of more than 4 weeks' duration may moderately increase the occurrence of cryptorchidism, especially when exposure occurs during the first and second trimesters (Jensen et al. 2010). These findings were confirmed by Kristensen et al. (2010) in a prospective birth cohort study including 2297 Danish and Finnish pregnant women reporting their use of mild analgesics. It was reported that in the Danish birth cohort the use of mild analgesics (including NA4AP) was dose dependently associated with congenital cryptorchidism and, in particular, use during the second trimester increased the risk. The association was not found in the Finnish birth cohort. Because the birth prevalence of cryptorchidism in Finland $(2.4 \%)$ is lower than that in Denmark (9.0\%), the authors reported that the study may be statistically underpowered to find an association in the Finnish cohort (Kristensen et al. 2010). Data from a French birth cohort study, published by Philippat et al. (2011), reported that the association between maternal use of mild analgesics during pregnancy and undescended testis risk was similar to that in the Danish population described by Kristensen et al. (2010) before adjustment for maternal age, gestational duration, maternal smoking, and other factors, but weaker after adjustment. However, this study was limited by small sample size, inability to distinguish between specific analgesics, and lack of information on dose, mixture, and exact timing of use (Philippat et al. 2011). The suggestion that intrauterine exposure to mild analgesics, primarily NA4AP, during the second trimester of pregnancy is associated with an increased prevalence of cryptorchidism was also made from the data of a large population-based cohort study carried out in The Netherlands (the Generation R Study; Snijder et al. 2012). The authors reported several limitations of the study, mostly the limited number of cryptorchidism cases and also the definition of the different pregnancy periods. However, the strength of this study was its population-based approach, which enabled the assessment and the adjustment for a large number of potential confounders.

\section{Metabolism of acetaminophen and aniline}

Between 75 and $86 \%$ of an oral aniline dose is excreted as NA4AP, mostly in its conjugated forms in urine, as confirmed by animal experiments. Human data show that if NA4AP is taken directly (for example, after therapeutic use of acetaminophen), very similar amounts of NA4AP are excreted renally: $\sim 3 \%$ free NA4AP, $\sim 40 \%$ NA4AP glucuronide, and $\sim 35 \%$ NA4AP sulfate. As additional metabolites, NA4AP cysteine conjugate $(\sim 4 \%)$ and NA4AP mercapturate $(\sim 3 \%)$ have been reported (Ladds et al. 1987). Minor NA4AP metabolites include 3-hydroxy-NA4AP, 3-methoxy-NA4AP, 3-hydroxy-NA4AP-3-sulfate, 3-methoxy-NA4AP sulfate, and 3-methoxy-NA4AP glucuronide. After overdosing, the relative amounts of cysteine and mercapturic acid conjugates in urine are increased (Andrews et al. 1976). In 2005, N-arachinodyl-4-phenolamine (AM404) was identified as a possible metabolite of NA4AP. AM404 was built in brain and spinal cord homogenates from Wistar Hannover rats after exposure to $p$-aminophenol (Högestätt et al. 2008). At present, there are no data available concerning the occurrence of AM404 in humans. However, due to the chemical structure and the resulting highly lipophilic character of this metabolite, its occurrence in urine is unlikely.

Some differences in NA4AP metabolism in neonates, children, and adults have been reported. While in adults NA4AP glucuronide is the predominant conjugate (see above), in children the NA4AP sulfate conjugate $(\sim 47 \%)$ is more dominant than the NA4AP glucuronide conjugate $(\sim 13 \%)$ (Levy et al. 1975b, Miller et al. 1976, Peterson \& Rumack 1978). However, the altered metabolism of NA4AP in children when compared with that in adults does not seem to affect its general rate of elimination. Plasma disappearance (elimination 
half-time) of NA4AP is comparable in adults (1.5-3.0 h) and children (1.0-3.5 h), with a slight prolongation of its half-life in neonates (2.2-5.0 h) (Miller et al. 1976, Peterson \& Rumack 1978). The similar metabolic pattern of NA4AP and aniline makes it difficult to determine whether the NA4AP present in urine is due to exposure to aniline, to NA4AP, or to both substances. Only specific metabolites leading from aniline (or possibly other precursors) to NA4AP might allow a differentiation between direct NA4AP intake and NA4AP generated through precursors. Such metabolites might be acetanilide, the aminophenols, or their conjugates (see Fig. 1). Acetanilide has been determined by Dierkes et al. (2014) and could only be found in the urine samples of individuals after aniline exposure, but not in those of any individuals from the general population.

\section{HBM methods for NA4AP}

HBM is defined as the determination of chemical substances or their metabolites in human body fluids such as blood and urine for measuring exposure to chemical substances for risk assessment and risk management (Angerer et al. 2007). Although NA4AP has been used as a pain reliever and fever reducer for decades, despite the veterinary use of NA4AP and the high production and sale volumes, and despite the fact that NA4AP is the most important metabolite of aniline, there is a lack of HBM data on this substance.

To our knowledge, NA4AP has not yet been included in larger population-based HBM studies such as the German GerES (German Environmental Survey), the US NHANES (National Health and Nutrition Examination Survey), and the Canadian CHMS (Canadian Health Measures Survey). Camann et al. (2012) detected traces of NA4AP in nine deciduous molars of 21 children using a HPLC-MS/MS method after a neutral, basic, and acetic extraction procedure with acetonitrile to extract NA4AP from pulverized tooth crown. The measured concentrations ranged from $<0.5 \mathrm{ng} / \mathrm{g}$, which was also the limit of quantification (LOQ) of the method used, to $17.3 \mathrm{ng} / \mathrm{g}$, with the median being less than LOQ and a 95th percentile of $10.8 \mathrm{ng} / \mathrm{g}$. According to the authors, the NA4AP concentrations were consistent with the NA4AP intake estimated from exposure questionnaires completed by the mothers. Therefore, the authors suggested that NA4AP appears to accumulate in deciduous molars and thus is an apparent biomarker of exposure to NA4AP in the first year after birth (Camann et al. 2012). We have recently published an analytical method for the determination of NA4AP in urine based on online extraction via turbulent-flow chromatography coupled with LC-MS/MS (Modick et al. 2013). In a HBM pilot study, we applied this method to analyze the urine samples of 21 individuals from the general German population. Before the study, all the volunteers completed a questionnaire about their in use of
NA4AP or NA4AP-containing products. NA4AP was detected in all the samples analyzed, with a wide concentration range from 8.7 to $22120 \mu \mathrm{g} / \mathrm{l}$ and a median of $85.7 \mu \mathrm{g} / \mathrm{l}$. We detected NA4AP even in the samples of those volunteers who indicated that they had never taken NA4AP and reported a considerable overlap in NA4AP concentrations, no matter whether the individual had or had not taken NA4AP during the week before sample collection. These findings were confirmed by our group in a second HBM pilot study investigating N4AP, the aniline-specific metabolite acetanilide, and the tentative aniline metabolite $\mathrm{N}$ acetyl-2-aminophenol (Dierkes et al. 2014). In this study, we confirmed the presence of NA4AP in urine samples obtained from individuals with no occupational aniline exposure or paracetamol medication. Not surprisingly, though, NA4AP was detected in high concentrations in the urine samples of two individuals using paracetamol medication and six volunteers with known occupational aniline exposure. Contrary to NA4AP, acetanilide the metabolic precursor of NA4AP - was only detected after exposure to aniline. $\mathrm{N}$-acetyl-2-aminophenol was detected in most of the samples, but without any relation to aniline exposure or correlation with the other two aniline metabolites. Apart from these studies, we are not aware of any other HBM measurements of NA4AP in the general population.

\section{The quest for possible NA4AP sources by means of HBM}

Currently, there are no indications that NA4AP is an endogenous substance naturally occurring in the human metabolism. For the purpose of identifying the possible sources of internal body burdens of NA4AP, we determined urinary concentrations of NA4AP in different experimental settings. All urine samples described in the following were analyzed using HPLC-MS/MS methods via isotope dilution quantification, developed and refined by our group (Modick et al. 2013, Dierkes et al. 2014). All the following values reflect total NA4AP in urine after enzymatic hydrolysis of the glucuronide and sulfate conjugates. All urinary analyses referred to in the following have been covered by various ethical approvals of the Medical Faculty of the Ruhr-Universität Bochum, Germany (reg. no.: 3867-10; reg. no.: 433312; and reg. no.: 4730-13).

\section{Analytical method}

A detailed description of our analytical method can be found in Dierkes et al. (2014). In short, all the urine samples were vortex-mixed before transferring the aliquots into silanized screw cap vials. After adding incubation buffer (ammonium acetate, $\mathrm{pH}$ 5.5-6.0), internal standard solution (deuterium-labeled analogs of 
NA4AP and acetanilide), and glucuronidase/arylsulfatase solution (for enzymatic cleavage of glucuronide and sulfate conjugates), the samples were incubated at $37^{\circ} \mathrm{C}$ in a water bath for $3.5 \mathrm{~h}$. Urinary creatinine concentrations were determined according to the method of Jaffé (1886).

Urine sample analysis was carried out using a Waters HPLC system coupled with a Waters Quattro Premier XE triple quadrupole mass spectrometer in a two-column switching assembly, which allowed online cleanup and analyte enrichment followed by chromatographic separation and mass spectrometric detection in one step. A Waters Oasis HLB cartridge column $(2.1 \times 20 \mathrm{~mm}$; $25 \mu \mathrm{m})$ was used for cleanup and enrichment; chromatographic separation was carried out on a Thermo Scientific (Franklin, MA, USA) Hypercarb column $(2.1 \times 100 \mathrm{~mm}$; $3 \mu \mathrm{m}$ ) by gradient elution with $3 \mathrm{mM}$ ammonium bicarbonate solution in water and acetonitrile as solvents. Mass spectrometric detection was conducted by electron spray ionization in positive ionization mode. Argon was used as the collision gas for MS/MS measurements. Fragmentation patterns of the analytes and internal standards were obtained by full-scan experiments. Based on the parent ions, two mass transitions were confirmed and optimized manually. The mass transition with the highest intensity was used for quantification (quantifier), whereas that with the second highest intensity was used to confirm the results of the quantifier ion.

Calibration was performed with standard solutions in water. Calibration standards were treated similarly to the urine samples. Calibration curves were obtained by plotting the quotient of peak areas of NA4AP or acetanilide and their deuterium-labeled analogs as a function of their concentration with a $1 / x$-weighting. Intraday precision was determined by analyzing quality control urine samples (prepared in our laboratory) eight times in a row at two concentration levels ( $Q_{\text {high }}$ and $Q_{\text {low }}$ ). Interday precision was determined by analyzing the control urine samples on eight different days using newly prepared calibration samples and calibration curves. Calculated deviations of intraday and interday precision measurements were below $15 \%$ for both analytes at both concentrations. The accuracy of the method was determined by analyzing eight urine samples with varying creatinine concentrations. These samples were analyzed in native condition and spiked at two concentration levels. The mean recoveries were between 105 and $114 \%$ for both analytes at both concentrations. Imprecisions calculated from the spiking experiments were in the range of intraday and interday precision data, underlining the ruggedness of the method. The limit of detection (LOD) was estimated on the basis of a signal-to-noise ratio of 3:1, and the LOQ was determined on the basis of a signal-to-noise ratio of 9:1. The LOD for acetanilide in urine was estimated to be $0.03 \mu \mathrm{g} / \mathrm{l}$ and the LOQ was $0.09 \mu \mathrm{g} / \mathrm{l}$. The LOQ for NA4AP was set to the lowest aqueous calibration point $(0.5 \mu \mathrm{g} / \mathrm{l})$. However, NA4AP concentrations in all the urine samples investigated until now are usually more than tenfold above this LOQ.

\section{Urinary NA4AP excretion in the general population}

In our daily laboratory routine, we have analyzed 2098 spot urine samples of the general population for determining the concentrations of NA4AP so far. These urine samples originated from various adult and control populations present in our institute. These samples, although collected from the general population, cannot be considered to be fully representative of the general population. Individuals were presumably not pregnant and occupationally not exposed to aniline. We had no information on the usage of acetaminophen or other pain relievers. The smoking status was assessed via urinary cotinine concentrations. All statistical analyses were carried out using IBM SPSS Statistics, version 20. NA4AP was detected in all the samples analyzed, at a broad range of concentrations, whereas acetanilide could not be detected in any of the samples. The distribution of NA4AP concentrations over all the individuals is shown in Fig. 2A. Urinary NA4AP concentrations were not normally distributed before and after logarithmic transformation by the Kolmogorov-Smirnov test. Therefore, we divided the population into two groups, using a cutoff value of $4000 \mu \mathrm{g} / \mathrm{l}$ NA4AP: a high-exposure group (c (NA4AP) $>4000 \mu \mathrm{g} / \mathrm{l} ; n=106$ : 56 smokers and 50 nonsmokers) and a low-exposure group (c (NA4AP) $<4000 \mu \mathrm{g} / \mathrm{l} ; n=1992: 996$ smokers and 996 nonsmokers). This cutoff value reflected the 95th percentile of the NA4AP concentration across all the samples. Additionally, according to the elimination kinetics of NA4AP, urinary NA4AP concentrations of $4000 \mu \mathrm{g} / \mathrm{l}$ would be caused by a single tablet of $500 \mathrm{mg}$ acetaminophen taken $36-48 \mathrm{~h}$ before sampling. Within these two groups, NA4AP concentrations were normally distributed as assessed by the Kolmogorov-Smirnov test

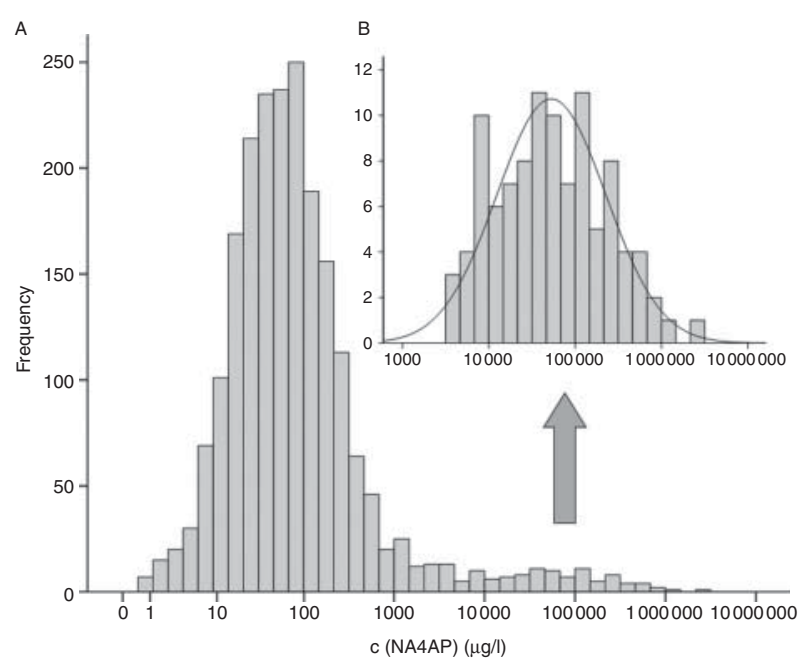

Figure 2 Distribution of urinary NA4AP concentrations in random spot urine samples obtained from the general population: (A) all samples $(n=2098)$ and (B) samples of the high-exposure group $(n=106$; c $>4000 \mu \mathrm{g} / \mathrm{l})$. Line indicates normal distribution curve. 
Table 3 Urinary NA4AP concentrations in the general population.

\begin{tabular}{lccc}
\hline & $\begin{array}{c}\text { Smokers } \\
(n=1052)\end{array}$ & $\begin{array}{c}\text { Nonsmokers } \\
(n=1046)\end{array}$ & $\begin{array}{c}\text { Total } \\
(n=2098)\end{array}$ \\
\hline Mean $(\mu \mathrm{g} / \mathrm{l})$ & 10834 & 4116 & 7484 \\
Median $(\mu \mathrm{g} / \mathrm{l})$ & 68.2 & 54.2 & 61.7 \\
Min. $(\mu \mathrm{g} / \mathrm{l})$ & 0.65 & 0.95 & 0.65 \\
Max. $(\mu \mathrm{g} / \mathrm{l})$ & 2274296 & 580358 & 2274296 \\
$25 \mathrm{P}(\mu \mathrm{g} / \mathrm{l})$ & 29.9 & 21.6 & 25.3 \\
$75 \mathrm{P}(\mu \mathrm{g} / \mathrm{l})$ & 164.5 & 150.3 & 155.6 \\
$95 \mathrm{P}(\mu \mathrm{g} / \mathrm{l})$ & 4464 & 3504 & 4093 \\
\hline
\end{tabular}

after logarithmic transformation. The distribution for the high-exposure group is shown in Fig. 2B. If we considered the distribution curve shown in Fig. $2 \mathrm{~B}$ (with NA4AP concentrations in the $\mathrm{mg} / \mathrm{l}$ range) indicative of therapeutic acetaminophen intake and used urinary NA4AP concentrations above $4000 \mu \mathrm{g} / \mathrm{l}$ as an arbitrary cutoff, $\sim 5 \%$ of the $>2000$ individuals investigated would have taken NA4AP before sampling.

Urinary NA4AP concentrations divided into the subgroups of smokers and nonsmokers and total population are given in Table 3. NA4AP concentrations differed significantly between the two groups according to the Mann-Whitney $U$ test $(P=0.01 ; \alpha=0.05)$ with a median NA4AP concentration of $68.2 \mu \mathrm{g} / \mathrm{l}$ in smokers compared with $54.2 \mu \mathrm{g} / \mathrm{l}$ in the nonsmokers. After splitting the population into the two NA4AP groups, the significant effect of smoking behavior on NA4AP excretion continued to hold, especially for the group with NA4AP concentrations $<4000 \mu \mathrm{g} / \mathrm{l}(P=0.01 ; \alpha=0.05)$.

The influence of smoking behavior on NA4AP excretion could be explained by NA4AP being the major metabolite of aniline and aniline being a known constituent of tobacco smoke. However, several previous HBM studies have reported no significant impact of smoking behavior on urinary aniline excretion (Riffelmann et al. 1995, Weiss \& Angerer 2002, Kütting et al. 2009). These contradictory findings might be explained by the relatively small effect of smoking on NA4AP (and possibly aniline) excretion that can only be detected in larger population studies. Additionally, NA4AP might be more appropriate to detect such an effect because it is the major metabolite of aniline and excreted in considerably higher concentrations than aniline (or its conjugates). On comparing median levels of smokers with those of nonsmokers, the urinary NA4AP concentrations of smokers were found to be $25 \%$ higher than those of the nonsmokers. The detection of NA4AP in the urine samples of nonsmokers and higher concentrations in the urine samples of smokers leads to the conclusion that smoking does indeed contribute to urinary NA4AP excretion, but that it is not its main source. This is supported by the lack of the aniline-specific metabolite acetanilide in the samples, which hints at other (additional) sources that might contribute to urinary NA4AP excretion. It is also congruent with the HBM pilot study carried out by Dierkes et al. (2014), where acetanilide could not be detected in samples obtained from the general population, but could be detected only in the urine samples of individuals with high exposure to aniline.

\section{Urinary NA4AP excretion after acetaminophen use}

We investigated the urinary elimination characteristics of NA4AP in one individual (male, 31 years, nonsmoker) after oral intake of a single tablet of acetaminophen containing $500 \mathrm{mg}$ NA4AP. One pre-dose urine sample was collected immediately before intake. We continuously collected urine samples for $48 \mathrm{~h}$ after intake. The urinary NA4AP concentrations over time are shown in Fig. 3. Urinary NA4AP concentrations reached maximum levels of $\sim 400 \mathrm{mg} / \mathrm{l}$ between 4 and $12 \mathrm{~h}$ after intake. NA4AP concentrations declined thereafter in a rather monotonic manner (indicative of a single phasic elimination), but remained in the $\mathrm{mg} / \mathrm{l}$ range until $\sim 36 \mathrm{~h}$ after intake (Fig. 3). Urinary NA4AP concentrations after intake are comparable to the findings reported by Dierkes et al. (2014) from two individuals who had used NA4AP medication $\sim 24 \mathrm{~h}$ before sampling, which contributed to urinary NA4AP concentrations of 160 and $275 \mathrm{mg} / \mathrm{l}$. Acetanilide could not be detected in any of these samples.

\section{NA4AP excretion after occupational aniline exposure}

Four individuals (two males and two females, aged 25-45 years, nonsmokers living in the greater area of Bochum, Germany) were exposed to aniline in an occupational

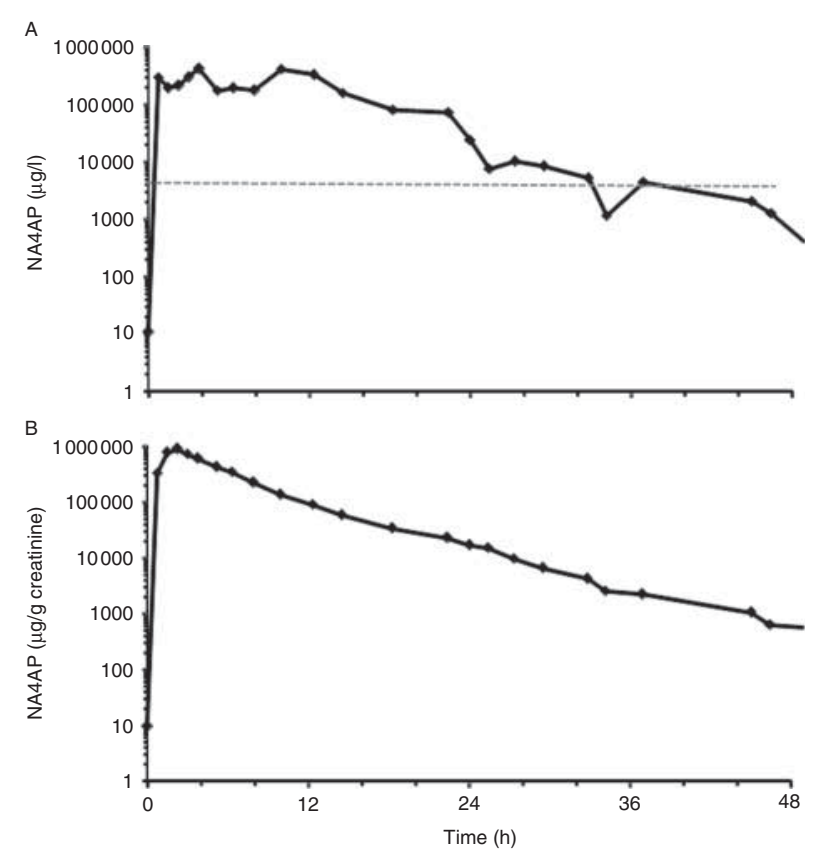

Figure 3 Urinary NA4AP concentrations after oral intake of $500 \mathrm{mg}$ on a semi-logarithmic scale: (A) NA4AP concentrations $(\mu \mathrm{g} / \mathrm{l})$ and $(\mathrm{B})$ creatinine-adjusted NA4AP concentrations. Dotted line indicates the 95th percentile of NA4AP concentrations over the analyzed population samples $(4000 \mu \mathrm{g} / \mathrm{l})$. 
setting via air for $8 \mathrm{~h}$ at the occupational threshold limit value $\left(7.7 \mathrm{mg} / \mathrm{m}^{3}\right.$ air), as that occurring, for example, in the rubber industry during the vulcanization process of rubber products (Korinth et al. 2006). Complete urine voids were collected before, during, and $16 \mathrm{~h}$ after exposure. The volunteers recorded the time and the void of each individual sample. All four individuals did not use NA4AP-containing medications in the week before and during the study. The urinary NA4AP and acetanilide concentrations (in $\mu \mathrm{g} / \mathrm{l}$ ) and the creatinineadjusted concentrations over time for all the four individuals are shown in Fig. 4. Before (occupational) aniline exposure, urinary NA4AP concentrations in all the participants were in the same range as in the general population, ranging from 40 to $170 \mu \mathrm{g} / \mathrm{g}$ creatinine $(15-80 \mu \mathrm{g} / \mathrm{l})$, whereas urinary acetanilide concentrations where below the LOQ $(0.09 \mu \mathrm{g} / \mathrm{l})$. Urinary NA4AP concentrations increased steadily during exposure and reached maximum levels of 55 000-75000 $\mathrm{\mu g} / \mathrm{g}$ creatinine $(10000-60000 \mu \mathrm{g} / \mathrm{l})$ between 10 and $13 \mathrm{~h}$ after the start of the study. Excretion maxima occurred about $2-5 \mathrm{~h}$ after the 8-h exposure window.

Urinary acetanilide excretion followed a similar pattern, except that acetanilide concentrations were about 100-200 times lower than NA4AP concentrations, peaking at $100-300 \mu \mathrm{g} / \mathrm{l}$. This is in good agreement with the findings of our previous HBM pilot study (Dierkes et al. 2014).

In conclusion, from this small and preliminary occupational aniline exposure study, we report urinary NA4AP concentrations well in the $\mathrm{mg} / \mathrm{l}$ range (up to $60 \mathrm{mg} / \mathrm{l}$ or $75 \mathrm{mg} / \mathrm{g}$ creatinine) occurring after legally permissible occupational exposure to aniline. Maximum urinary NA4AP concentrations were less than ten times below the maximum levels observed after the therapeutic use of a single $500 \mathrm{mg}$ tablet of acetaminophen.

\section{NA4AP excretion during a controlled 2-day fasting study}

We hypothesized above that contaminated foodstuffs (with either NA4AP itself or precursors such as aniline) may be a possible reason for NA4AP excretion in the general population. To investigate the influence of food intake on NA4AP excretion, we carried out a 48-h fasting study. We have previously used the urine samples collected in this study to investigate the influence of foodstuffs on urinary excretion of phthalate metabolites and bisphenol A (Christensen et al. 2012, Koch et al. 2013). For detailed information on study design and execution, see these publications. In short, study volunteers were five healthy employees of our institute, all living in the area of Bochum (Germany), ages ranging from 27 to 47 years (two males and three females; body weight: 60-92 kg). One volunteer was excluded from this study because questionnaire records indicated that this volunteer had possibly taken an
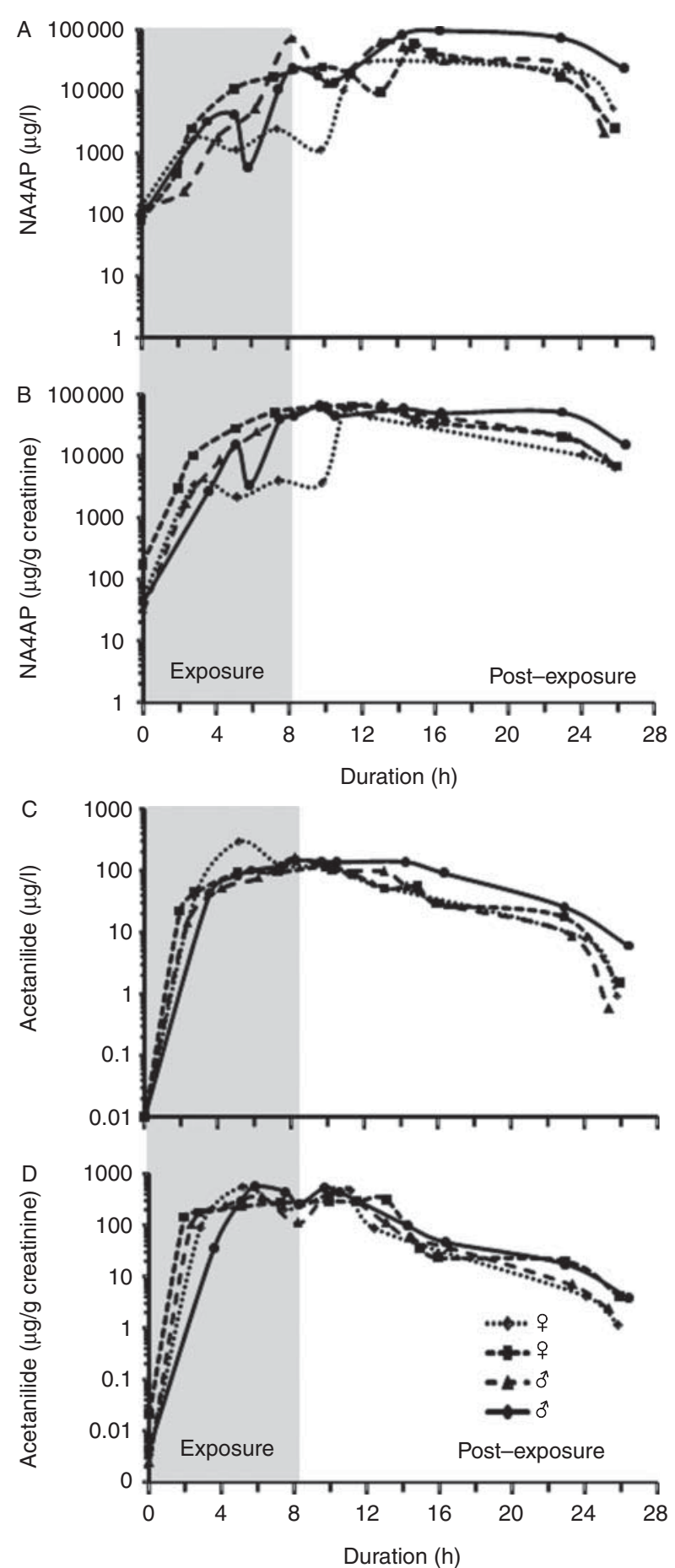

Figure 4 Urinary NA4AP concentrations in four volunteers during and after aniline exposure in an occupational setting: (A) NA4AP concentrations $(\mu \mathrm{g} / \mathrm{l})$; (B) creatinine-adjusted NA4AP concentrations; (C) acetanilide concentrations ( $\mu \mathrm{g} / \mathrm{l})$; and (D) creatinine-adjusted acetanilide concentrations.

NA4AP-containing medication during the week before the study and during the study. The remaining four volunteers (two males and two females) consisted of three nonsmokers and one smoker, who refrained from 
smoking several days before and during the study. The volunteers collected full volume urine samples over the course of the 48-h fasting phase, as well as samples before and after the fasting phase. Fasting itself excluded intake of any foodstuff (as well as food-related items, for example, chewing gum) and the intake of any liquids, except bottled mineral water. The timing and quantity of intake of mineral water were not regulated. The use of personal care products and use of any medications were not regulated, but were documented. None of the volunteers had known occupational exposure to aniline (Koch et al. 2013).

Three of the volunteers (one male and two females) started fasting at $\sim 1300 \mathrm{~h}$ after dining together on individual different meals. One volunteer started fasting the following day after a separate meal. One urine sample was collected before fasting (pre-fasting sample), and the volunteer started fasting immediately after the meal $(t=0 \mathrm{~h})$.

The urinary NA4AP concentrations (in $\mu \mathrm{g} / \mathrm{l}$ and creatinine adjusted) of the four volunteers over the duration of the study are shown in Fig. 5. One can clearly see the influence of fasting (and preceding and following food intake) on the urinary excretion pattern of NA4AP. At the start of the study, the urinary NA4AP concentrations of the volunteers ranged from 3 to $1700 \mu \mathrm{g}$ NA4AP/g creatinine $(10-1100 \mu \mathrm{g} / \mathrm{l})$. In all the volunteers, urinary NA4AP concentrations increased after the pre-fast meal, reaching maximum values ranging from 700 to $5000 \mu \mathrm{g}$ NA4AP/g creatinine $(1100-5300 \mu \mathrm{g} / \mathrm{l}) \sim 2.5-6 \mathrm{~h}$ after the last meal. These values are of the same order of magnitude as the urinary concentrations in the general population

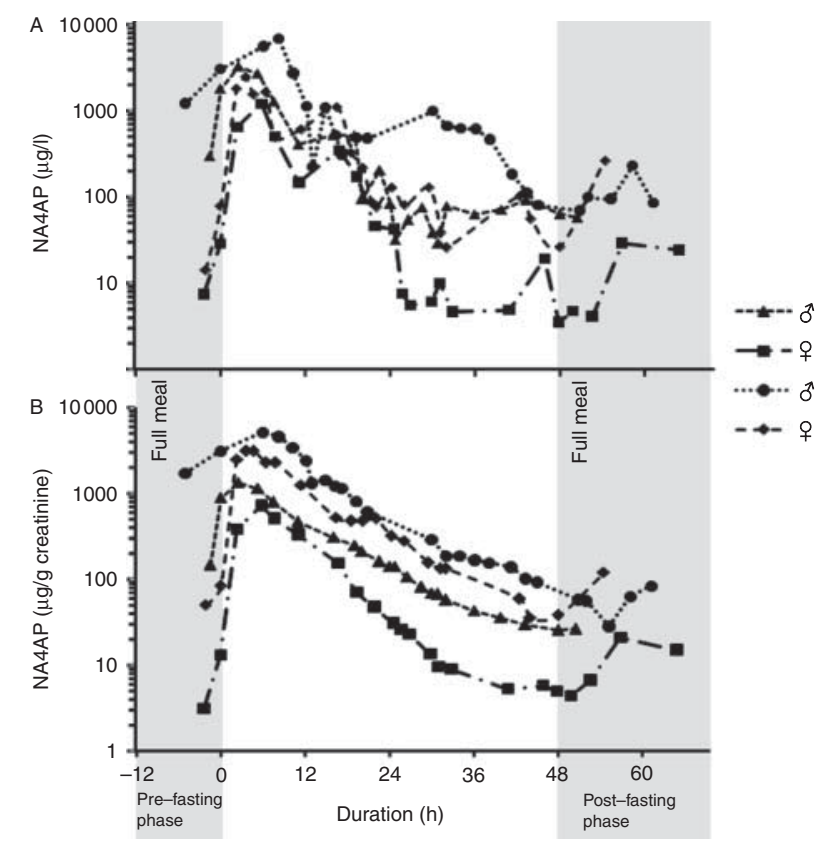

Figure 5 Urinary NA4AP concentrations in four volunteers during a controlled 48-h fasting study. (A) NA4AP concentrations ( $\mu \mathrm{g} / \mathrm{l}$ ) and (B) creatinine-adjusted NA4AP concentrations. described previously by us (Modick et al. 2013), although at the upper range. During fasting, urinary NA4AP concentrations in all the volunteers decreased considerably by a factor of $50-100$, reaching minimum values of 5-70 $\mu \mathrm{g} \mathrm{NA4AP/g}$ creatinine $(5-75 \mu \mathrm{g} / \mathrm{l})$ at the end of the fast. After the volunteers resumed eating, urinary NA4AP concentrations rose again (Fig. 5). Taken together, the data obtained in this study impressively hint that food is one possible, major source of internal body burdens of NA4AP in the general population. However, whether direct ingestion of NA4AP or NA4AP precursors such as aniline leads to the changes observed in urinary NA4AP concentrations has not been elucidated yet. In all the samples, acetanilide concentrations were below the LOD $(0.03 \mu \mathrm{g} / \mathrm{l})$.

\section{Other possible NA4AP sources}

As has been pointed out already, aniline is an important building block for several substances, such as pesticides and colorants (azo-dyes), that the general population is continuously exposed to. During the metabolism of these substances, free aniline might be released and further metabolized to NA4AP. A summary of possible aniline and therefore possible NA4AP precursors, according to a publication of the German Federal Ministry of Environment (2011), is given in Supplementary Table 1 (see section on supplementary data given at the end of this article). However, this list is not considered to be exhaustive. Environmental NA4AP might also be contributing to the low urinary background concentrations. For example, NA4AP and its metabolites respectively were detected in water samples from several rivers in Spain and Portugal at levels in the low $\mu \mathrm{g} / \mathrm{l}$ range (López-Serna et al. 2010, Santos et al. 2013).

\section{Conclusions}

We confirmed the results of our previous studies reporting the ubiquitous excretion of NA4AP in urine in the general population (Modick et al. 2013). Using measurements of more than 2000 urine samples, we determined a median NA4AP excretion of around $60 \mu \mathrm{g} / \mathrm{l}$. However, urinary NA4AP concentrations well into the $\mathrm{mg} / \mathrm{l}$ range can still be observed in individuals with no obvious NA4AP exposure such as intake of NA4AP-containing medications (or occupational aniline exposure). As shown by the distribution of the NA4AP values in the 2000 urine samples obtained from the general population as well as the defined dosing of one tablet of acetaminophen, urinary NA4AP concentrations above $4000 \mu \mathrm{g} / \mathrm{l}$ hint at the direct intake of NA4AP through medication (within the last 36-48 h). Recent acetaminophen users exhibit urinary NA4AP concentrations close to the $\mathrm{g} / \mathrm{l}$ range. However, $4000 \mu \mathrm{g}$ NA4AP per liter urine can only be regarded as a soft cutoff 
between acetaminophen users and nonusers, as concentrations above this value might also be caused by food intake (as shown by our volunteer fasting study) or occupational aniline exposure. On the other hand, two days after medication related acetaminophen uptake, urinary NA4AP concentrations can drop below $1000 \mu \mathrm{g} / \mathrm{l}$.

The sources of ubiquitous internal body burden of NA4AP in the general population remain obscure. However, our research hints at several possible sources: i) direct intake of acetaminophen or acetaminophencontaining pharmaceuticals as a primary source for high urinary NA4AP concentrations; ii) occupational exposure to aniline, leading to NA4AP as the major aniline metabolite; iii) ubiquitous exposure to environmental sources, for example, nutrition, possibly containing NA4AP itself or aniline and other NA4AP precursors; and iv) smoking, most probably through aniline, which is present in both mainstream and sidestream cigarette smoke. Until now, we are not fully aware of the underlying mechanisms of nutrition being a source of urinary NA4AP excretion.

The ubiquitous background excretion of NA4AP in the general population is not implausible. We summarized the broad use of NA4AP in human medicine above and also speculated about its use in veterinary medicine. Ubiquitous aniline exposure in the general population has been described previously, and NA4AP has been known to be the major metabolite of aniline for a long time. One major task for the future is to disentangle and quantify the contribution of each possible source to the total ubiquitous NA4AP excretion.

From the toxicological perspective, the omnipresence of a pharmacologically active substance, which is, to our knowledge, not naturally occurring in the human body, raises some concern, as recent animal and human studies indicate anti-androgenic effects of NA4AP and suggest NA4AP to be a possible risk factor for male developmental disorders in humans. Further evaluation of our findings of an omnipresent NA4AP excretion depends upon at least two key questions. i) Can it be confirmed (by both mechanistic and epidemiological studies) that therapeutic doses of NA4AP cause detrimental effects in male human offspring? ii) Are urinary NA4AP concentrations in the $\mathrm{mg} / \mathrm{l}$ range (as observed in non-acetaminophen users and aniline-exposed individuals) indicative of NA4AP doses of possible toxicological relevance?

Therefore, to fully understand and investigate the sources and routes of exposure as well as the resulting toxicological impacts, an interdisciplinary approach in this matter is warranted. At this point, HBM can play an important role in the assessment of NA4AP exposure in specific cohorts, populations, and subpopulations, in the investigation of differences and similarities in NA4AP and aniline metabolism, and in the confirmation or refutation of links between NA4AP exposure and possible (adverse) effects.

\section{Discussion from meeting}

Tue Søeborg (Copenhagen, Denmark): I am confused by your term 'body burden' when you measure urinary levels. If aniline is converted to paracetamol, have you measured levels in the serum and how much of it is bioavailable?

H M Koch (Bochum, Germany): Serum measurements would be useful, but we have not done that. Paracetamol was discovered following a study of aniline exposure when the primary metabolite was found to be active and this is a precursor of paracetamol. Therefore, if the paracetamol in our assay was derived from aniline, then the precursor will also be active, indicating a pharmacologically active body burden.

Bernard Jègou (Rennes, France): We have just published a paper (Albert et al. 2013) indicating that paracetamol inhibits testosterone synthesis in the adult testis. Some elite athletes consume large quantities of paracetamol. Aspirin and paracetamol are not banned substances in athletics, and high concentrations can be used for preventative and curative muscle problems. However, we do not know what is happening in the long term, and its effect on performance might be counterproductive if there is a chronic reduction in testosterone even in the presence of muscle repair.

Andreas Kortenkamp (Uxbridge, UK): I believe that aniline workers do not suffer pain. The endocrine disrupter effect of paracetamol was confirmed by our epidemiological questionnaire survey indicating that paracetamol use was associated with cryptorchidism but not with hypospadias, and we plan to verify the questionnaire responses by conducting urine analyses. Do you think that this approach is naïve because your study shows ubiquitous exposure to paracetamol?

H M Koch: We can differentiate between individuals with low-level exposure and excessive exposure to paracetamol. This is valuable information and we see paracetamol users having urinary excretion in the g/l range.

Shanna Swan (New York, USA): Waste water in Israel is reused and is high in pharmaceuticals. Is water a possible source of paracetamol exposure?

H M Koch: Probably not, because at the present level in water, we would need to drink hundreds of liters to reach the concentration found in urine in our study. Water in Germany is tested for pharmaceuticals. However, there might be sufficient aniline, aniline derivatives, and/or paracetamol in the diet to explain the urinary levels observed in our study. Regarding paracetamol in the diet, paracetamol is approved for veterinary use in the European Union. There is no specific maximum residue limit for paracetamol in foodstuffs of animal origin. 


\section{Supplementary data}

This is linked to the online version of the paper at http://dx.doi. org/10.1530/REP-13-0527.

\section{Declaration of interest}

The authors declare that there is no conflict of interest that could be perceived as prejudicing the impartiality of the review.

\section{Funding}

This review did not receive any specific grant from any funding agency in the public, commercial or not-for-profit sector. This article is based on the work presented at the 7th Copenhagen Workshop on Endocrine Disrupters, which was supported by the Danish Ministry of the Environment Environmental Protection Agency. Publication of this special issue was supported by the Society for Reproduction and Fertility. H M Koch received funding for travel and accommodation for the COW conference. All other authors declare no relationship with the sponsors of the conference.

\section{References}

Albert O, Desdoits-Lethimonier C, Lesne L, Legrand A, Guille F, Bensalah K, Dejucq-Rainsford N \& Jegou B 2013 Paracetamol, aspirin and indomethacin display endocrine disrupting properties in the adult human testis in vitro. Human Reproduction 28 1890-1898. (doi:10.1093/humrep/det112)

Amateau SK \& McCarthy MM 2004 Induction of PGE2 by estradiol mediates developmental masculinization of sex behavior. Nature Neuroscience 7 643-650. (doi:10.1038/nn1254)

Andrews RS, Bond CC, Burnett J, Saunders A \& Watson K 1976 Isolation and identification of paracetamol metabolites. Journal of International Medical Research 4 34-39.

Angerer J, Ewers U \& Wilhelm M 2007 Human biomonitoring: state of the art. International Journal of Hygiene and Environmental Health $\mathbf{2 1 0}$ 201-228. (doi:10.1016/j.ijheh.2007.01.024)

el-Bayoumy K, Donahue JM, Hecht SS \& Hoffmann D 1986 Identification and quantitative determination of aniline and toluidines in human urine. Cancer Research 46 6064-6067.

Berlin CM, Yaffe SJ \& Ragni M 1980 Disposition of acetaminophen in milk, saliva, and plasma of lactating women. Pediatric Pharmacology 1 135-141.

Bitzén PO, Gustafsson B, Jostell KG, Melander A \& Wåhlin-Boll E 1981 Excretion of paracetamol in human breast milk. European Journal of Clinical Pharmacology 20 123-125. (doi:10.1007/BF00607148)

Black RA \& Hill DA 2003 Over-the-counter medications in pregnancy. American Family Physician 67 2517-2524.

Camann DE, Schultz ST, Yau AY, Heilbrun LP, Zuniga MM, Palmer RF \& Miller CS 2012 Acetaminophen, pesticide, and diethylhexyl phthalate metabolites, anandamide, and fatty acids in deciduous molars: potential biomarkers of perinatal exposure. Journal of Exposure Science \& Environmental Epidemiology 23 190-196. (doi:10.1038/jes.2012.71)

Christensen KLY, Lorber M, Koslitz S, Brüning T \& Koch HM 2012 The contribution of diet to total bisphenol A body burden in humans: results of a 48 hour fasting study. Environment International 50 7-14. (doi:10. 1016/j.envint.2012.09.002)

Committee for Veterinary Medicinal Products 1999 Paracetamol Summary Report (http://www.ema.europa.eu/docs/en_GB/document_ library/Maximum_Residue_Limits_-_Report/2009/11/WC500015516.pdf). Last accessed 8 October 2013.

Dierkes G, Weiss T, Modick H, Käfferlein HU \& Brüning T 2014 N-acetyl-4aminophenol (paracetamol), $\mathrm{N}$-acetyl-2-aminophenol and acetanilide in urine samples from the general population, individuals exposed to aniline and paracetamol users. International Journal of Hygiene and Environmental Health. (http://dx.doi.org/10.1016/j.ijheh.2013.11.005)
Dikstein S, Zor U, Ruah D \& Sulman FG 1966 Stimulatory effect of paracetamol on chicken growth. Poultry Science 45 744-746. (doi:10.3382/ps.0450744)

European Commission 2010 Commission Regulation (EU) no. 37/2010 of 22 December 2009 on pharmacologically active substances and their classification regarding maximum residue limits in foodstuffs of animal origin. (http://ec.europa.eu/health/files/eudralex/vol-5/reg_2010 37/reg_2010_37_en.pdf). Last accessed 20 February 2014.

Federal Ministry of Food, Agriculture and Consumer Protection 2002 Jahresbericht 2002 zum Nationalen Rückstandskontrollplan. (http:// www.lua.sachsen.de/download/lua//B_2003.pdf). Last accessed 20 February 2014.

Foresta C, Zuccarello D, Garolla A \& Ferlin A 2008 Role of hormones, genes, and environment in human cryptorchidism. Endocrine Reviews 29 560-580. (doi:10.1210/er.2007-0042)

Gentili A, Caretti F, Bellante S, Mainero Rocca L, Curini R \& Venditti A 2012 Development and validation of two multiresidue liquid chromatography tandem mass spectrometry methods based on a versatile extraction procedure for isolating non-steroidal anti-inflammatory drugs from bovine milk and muscle tissue. Analytical and Bioanalytical Chemistry 404 1375-1388. (doi:10.1007/s00216-012-6231-0)

German Federal Ministry of Environment 2011 Stoffmonographie und Referenzwerte für monocyklische Aminoaromaten im Urin. Stellungnahme der Kommission Human-Biomonitoring des Umweltbundesamtes. Bundesgesundheitsblatt, Gesundheitsforschung, Gesundheitsschutz 54 650-663. (doi:10.1007/s00103-011-1256-7)

German Research Foundation 1992 Anilin (MAK Value Documentation in German language, 1992). (http://www.ecoserve.ch/uploads/media/ MAK_BAT_20141903_D_1_.pdf). Last accessed 20 February 2014.

Glaeske G, Janhsen K \& Schicktanz C 2009 GEK-Arzneimittel-Report 2009: Auswertungsergebnisse der GEK-Arzneimitteldaten aus den Jahren 2007 bis 2008, 1st edn. Sankt Augustin: Asgard. (http://www.barmer-gek.de/barmer/ web/Portale/Presseportal/Subportal/Infothek/Studien-und-Reports/GEKSchriftenreihe-Gesundheitsanalyse/Arzneimittel/PDF-Arzneimittel-Report2007, property=Data.pdf). Last accessed 20 February 2014.

Gupta C 1989 The role of prostaglandins in masculine differentiation: modulation of prostaglandin levels in the differentiating genital tract of the fetal mouse. Endocrinology 124 129-133. (doi:10.1210/endo-124-1-129)

Hinz B, Cheremina O \& Brune K 2007 Acetaminophen (paracetamol) is a selective cyclooxygenase-2 inhibitor in man. FASEB Journal 22 383-390. (doi:10.1096/fj.07-8506com)

Högestätt ED, Jönsson BAG, Ermund A, Andersson DA, Björk H, Alexander JP, Cravatt BF, Basbaum AI \& Zygmunt PM 2008 Conversion of acetaminophen to the bioactive $\mathrm{N}$-acylphenolamine AM404 via fatty acid amide hydrolase-dependent arachidonic acid conjugation in the nervous system. Journal of Biological Chemistry 290 31405-31412.

Hu T, Peng T, Li X, Chen D, Dai H, Deng X, Yue Z, Wang G, Shen J, Xia X et al. 2012 Simultaneous determination of thirty non-steroidal antiinflammatory drug residues in swine muscle by ultra-high-performance liquid chromatography with tandem mass spectrometry. Journal of Chromatography. A 1219 104-113. (doi:10.1016/j.chroma.2011.11.009)

Iwersen-Bergmann S \& Schmoldt A 2000 Acute intoxication with aniline: detection of acetaminophen as aniline metabolite. International Journal of Legal Medicine 113 171-174. (doi:10.1007/s004140050292)

Jaffé M 1886 Ueber den Niederschlag welchen Pikrinsaure in normalen Harn erzeugt und uber eine neue Reaction des Kreatinins. Physiological Chemistry 10391.

Jensen MS, Rebordosa C, Thulstrup AM, Toft G, Sørensen HT, Bonde JP, Henriksen TB \& Olsen J 2010 Maternal use of acetaminophen, ibuprofen, and acetylsalicylic acid during pregnancy and risk of cryptorchidism. Epidemiology 21 779-785. (doi:10.1097/EDE.0b013e3181f20bed)

Kao J, Faulkner J \& Bridges JW 1978 Metabolism of aniline in rats, pigs and sheep. Drug Metabolism and Disposition 6 549-555.

Koch HM, Lorber M, Christensen KLY, Pälmke C, Koslitz S \& Brüning T 2013 Identifying sources of phthalate exposure with human biomonitoring: results of a $48 \mathrm{~h}$ fasting study with urine collection and personal activity patterns. International Journal of Hygiene and Environmental Health 216 672-681. (doi:10.1016/j.ijheh.2012.12.002)

Korinth G, Weiss T, Penkert S, Schaller KH, Angerer J \& Drexler H 2006 Percutaneous absorption of aromatic amines in rubber industry workers: impact of impaired skin and skin barrier creams. Occupational and Environmental Medicine 64 366-372. (doi:10.1136/oem.2006.027755) 
Kristensen DM, Hass U, Lesne L, Lottrup G, Jacobsen PR, DesdoitsLethimonier C, Boberg J, Petersen JH, Toppari J \& Jensen TK 2010 Intrauterine exposure to mild analgesics is a risk factor for development of male reproductive disorders in human and rat. Human Reproduction $\mathbf{2 6}$ 235-244. (doi:10.1093/humrep/deq323)

Kristensen DM, Skalkam ML, Audouze K, Lesné L, Desdoits-Lethimonier C, Frederiksen H, Brunak S, Skakkebæk NE, Jégou B, Hansen JB et al. 2011 Many putative endocrine disruptors inhibit prostaglandin synthesis. Environmental Health Perspectives 119 534-541. (doi:10.1289/ehp. 1002635)

Kristensen DM, Lesné L, Le Fol V, Desdoits-Lethimonier C, DejucqRainsford N, Leffers H \& Jégou B 2012 Paracetamol (acetaminophen), aspirin (acetylsalicylic acid) and indomethacin are anti-androgenic in the rat foetal testis. International Journal of Andrology 35 377-384. (doi:10.1111/j.1365-2605.2012.01282.x)

Kütting B, Göen T, Schwegler U, Fromme H, Uter W, Angerer J \& Drexler H 2009 Monoarylamines in the general population - a crosssectional population-based study including 1004 Bavarian subjects. International Journal of Hygiene and Environmental Health 212 298-309. (doi:10.1016/j.ijheh.2008.07.004)

Ladds G, Wilson K \& Burnett D 1987 Automated liquid chromatographic method for the determination of paracetamol and six metabolites in human urine. Journal of Chromatography 414 355-364. (doi:10.1016/ 0378-4347(87)80060-9)

Landschneider C 2011 ROTE LISTE® 2011. Pharmazie in unserer Zeit 40286.

Levy G, Garrettson LK \& Soda DM 1975a Letter: Evidence of placental transfer of acetaminophen. Pediatrics $\mathbf{5 5} 895$

Levy G, Khanna NN, Soda DM, Tsuzuki O \& Stern L 1975b Pharmacokinetics of acetaminophen in the human neonate: formation of acetaminophen glucuronide and sulfate in relation to plasma bilirubin concentration and D-glucaric acid excretion. Pediatrics 55 818-825.

Lewalter J \& Korallus U 1985 Blood protein conjugates and acetylation of aromatic amines. New findings on biological monitoring. International Archives of Occupational and Environmental Health 56 179-196. (doi:10.1007/BF00396596)

López-Serna R, Pérez S, Ginebreda A, Petrović M \& Barceló D 2010 Fully automated determination of 74 pharmaceuticals in environmental and waste waters by online solid phase extraction-liquid chromatographyelectrospray-tandem mass spectrometry. Talanta 83 410-424. (doi:10.1016/j.talanta.2010.09.046)

Love DC, Halden RU, Davis MF \& Nachman KE 2012 Feather meal: a previously unrecognized route for reentry into the food supply of multiple pharmaceuticals and personal care products (PPCPs). Environmental Science \& Technology 46 3795-3802. (doi:10.1021/es203970e)

Mazaud-Guittot S, Nicolaz CN, Desdoits-Lethimonier C, Coiffec I, Maamar MB, Balaguer P, Kristensen DM, Chevrier C, Lavoué V, Poulain P et al. 2013 Paracetamol, aspirin and indomethacin induce endocrine disturbances in the human fetal testis capable of interfering with testicular descent. Journal of Clinical Endocrinology and Metabolism 98 E1757-E1767. (doi:10.1210/jc.2013-2531)

Miller RP, Roberts RJ \& Fischer LJ 1976 Acetaminophen elimination kinetics in neonates, children, and adults. Clinical Pharmacology and Therapeutics 19 284-294.

Modick H, Schütze A, Pälmke C, Weiss T, Brüning T \& Koch HM 2013 Rapid determination of $\mathrm{N}$-acetyl-4-aminophenol (paracetamol) in urine by tandem mass spectrometry coupled with on-line clean-up by two dimensional turbulent flow/reversed phase liquid chromatography. Journal of Chromatography. B, Analytical Technologies in the Biomedical and Life Sciences 925 33-39. (doi:10.1016/j.jchromb.2013.02.023)

Notarianni LJ, Oldham HG \& Bennett PN 1987 Passage of paracetamol into breast milk and its subsequent metabolism by the neonate. British Journal of Clinical Pharmacology 24 63-67. (doi:10.1111/j.1365-2125. 1987.tb03137.x)
Ortiz de García S, Pinto Pinto G, García Encina P \& Irusta Mata R 2013 Consumption and occurrence of pharmaceutical and personal care products in the aquatic environment in Spain. Science of the Total Environment 444 451-465. (doi:10.1016/j.scitotenv.2012.11.057)

Palmiotto G, Pieraccini G, Moneti G \& Dolara P 2001 Determination of the levels of aromatic amines in indoor and outdoor air in Italy. Chemosphere 43 355-361. (doi:10.1016/S0045-6535(00)00109-0)

Peterson RG \& Rumack BH 1978 Pharmacokinetics of acetaminophen in children. Pediatrics 62 877-879.

Philippat C, Giorgis-Allemand L, Chevrier C, Cordier S, Jégou B, Charles M \& Slama R 2011 Analgesics during pregnancy and undescended testis. Epidemiology 22 747-749. (doi:10.1097/EDE.0b013e318225bf33)

Rebordosa $C$, Kogevinas $M$, Horváth-Puhó $E$, Nørgård $B$, Morales $M$, Czeizel AE, Vilstrup H, Sørensen HT \& Olsen J 2008 Acetaminophen use during pregnancy: effects on risk for congenital abnormalities. American Journal of Obstetrics and Gynaecology 198 e1-e7. (doi:10.1016/j.ajog. 2007.08.040)

Riffelmann M, Müller G, Schmieding W, Popp W \& Norpoth K 1995 Biomonitoring of urinary aromatic amines and arylamine hemoglobin adducts in exposed workers and nonexposed control persons. International Archives of Occupational and Environmental Health 68 36-43. (doi:10.1007/BF01831631)

Santos LH, Paíga P, Araújo AN, Pena A, Delerue-Matos C \& Montenegro MC 2013 Development of a simple analytical method for the simultaneous determination of paracetamol, paracetamolglucuronide and $p$-aminophenol in river water. Journal of Chromatography. B, Analytical Technologies in the Biomedical and Life Sciences 930 75-81. (doi:10.1016/j.jchromb.2013.04.032)

Snijder CA, Kortenkamp A, Steegers EA, Jaddoe VW, Hofman A, Hass U \& Burdorf A 2012 Intrauterine exposure to mild analgesics during pregnancy and the occurrence of cryptorchidism and hypospadia in the offspring: the Generation R Study. Human Reproduction 27 1191-1201. (doi:10.1093/humrep/der474)

Thiele K, Kessler T, Arck P, Erhardt A \& Tiegs G 2013 Acetaminophen and pregnancy: short- and long-term consequences for mother and child. Journal of Reproductive Immunology 97 128-139. (doi:10.1016/j.jri. 2012.10.014)

Ward EM, Sabbioni G, DeBord DG, Teass AW, Brown KK, Talaska GG, Roberts DR, Ruder AM \& Streicher RP 1996 Monitoring of aromatic amine exposures in workers at a chemical plant with a known bladder cancer excess. Journal of the National Cancer Institute 88 1046-1052. (doi:10.1093/jnci/88.15.1046)

Weigand UW, Chou RC, Maulik D \& Levy G 1984 Assessment of biotransformation during transfer of propoxyphene and acetaminophen across the isolated perfused human placenta. Pediatric Pharmacology 4 145-153.

Weiss T \& Angerer J 2002 Simultaneous determination of various aromatic amines and metabolites of aromatic nitro compounds in urine for low level exposure using gas chromatography-mass spectrometry. Journal of Chromatography. B, Analytical Technologies in the Biomedical and Life Sciences 778 179-192. (doi:10.1016/S03784347(01)00542-4)

Werler M, Mitchell A, Hernandezdias S \& Honein M 2005 Use of over-thecounter medications during pregnancy. American Journal of Obstetrics and Gynecology 193 771-777. (doi:10.1016/j.ajog.2005.02.100)

Received 16 October 2013

First decision 7 November 2013

Revised manuscript received 13 December 2013

Accepted 22 January 2014 